\title{
Investigation of Iranian pomegranate cultivars for wound healing components
}

\author{
Mohammad Omidi Ghaleh Mohammadi (1), Sayid Mahdi Mirghazanfari (2)
}

(1) AJA University of Medical Sciences, Tehran, Iran ; (2) Department of Physiology and Iranian Medicine, School of Medicine, AJA University of Medical Sciences, Tehran, Iran

This article is distributed under the terms of the Creative Commons Attribution Noncommercial License (CC BY-NC 4.0) which permits any noncommercial use, distribution, and reproduction in any medium, provided the original author(s) and source are credited.

\begin{abstract}
One of the most important issues which medical science has been facing is wound healing for the tissue repair with the least complications. In this study, we aimed to isolate, purify and quantitate tannins and phenolic compounds from exocarp and pulp of fruits of Iranian pomegranate cultivars. Our findings demonstrate that the highest amount of tannin extracts from ethanol extract of the black peel exocarp was $201.76 \pm 1.93$. The highest amount of flavonoids from the ethanol extract of Sweet Alac exocarp was119.69 \pm 1.02 as well as antioxidant compounds activity in the exocarp and pulp showed that the highest activity is in the ethanol extract of the black peel was $95.65 \pm 3.1$. The total phenolic activity indicated that the Sour white peel ethanol extract has the highest phenolic activity $327.05 \pm 863$. Our data suggest that the ethanol extract of pomegranate exocarp has the higher amounts of tannins and flavonoids, compounds that are known to be beneficial for wound healing. Taken together, these data suggest that compounds isolated from Iranian pomegranate cultivars offer new options for managements of wound healing.
\end{abstract}

Key Words: Pomegranate cultivars, tannin, phenolic compounds, flavonoids, wound healing. Eur J Transl Myol 29 (1): 22-26, 2019

Wounds are among the most important reasons for occurring infections and diseases. Aiding fast repair of tissues and healing the wounds is a necessity in that way. Despite major progress in the treatment of surgical wounds, infection is still known as one of the most important reasons for deaths after surgery. ${ }^{1}$ Correct treatment and proper care of the wound healing with the aim of improving the speed of recovery, avoiding infections and preventing chronic wounds are always in the minds of practitioners, who use several methods to achieve these goals. ${ }^{2}$ A number of drugs and ointments are used to heal open wounds, and each of them has limitations and side effects. Iranian traditional medicine has been a very effective source of suggestions, with several medical books written on drugs for treating diseases, as seen in other traditional medicine practices. ${ }^{3}$ Many researches have recently studied traditional medicine products and their effects on wound healing and inflammation. ${ }^{4-5}$ Considering, the high number of Iranian pomegranate varieties and the importance of tannins and flavonoids in tissue repair and wound healing, identification of native pomegranate cultivars with the highest amount of tannin and phenolic compounds in the exocarp is a very promising approach. Thus, we isolated, purified and quantitated tannins and phenolic compounds from the exocarp and pulp of pomegranate fruit from several Iranian cultivars.

\section{Materials and Methods \\ Iranian pomegranate cultivars}

The most commercially harvested pomegranate cultivars in Iran, Sweet Alac, Sour Alac, Sour Malas, Sweet Black, Sour Summer, Sour White Peel, Sweet Saveh, Black Peel, Sweet White Peel, Agha Mohammad Ali, Sweet Shahsavar, Robab, Yousef Khani, and Sweet Aghdaei were obtained from Saveh Agricultural Research Center.

\section{Preparing extracts}

To prepare the extracts from the fruit, exocarp and pulp of the pomegranates were removed. The exocarps were placed in an oven at a temperature of $75^{\circ} \mathrm{C}$ for $24-48$ hours to completely dry. The soaking method was used to extract tannins in this study. ${ }^{6}$

Ascorbic acid (vitamin C)

To prepare 10 grams of extract, pomegranate exocarp and pulp were dissolved in $5 \%$ metaphosphoric acid and 
Table 1: Fruit weight (FW), skin weight $(\mathrm{SkW})$, skin percentage $(\mathrm{SkP})$ and Extraction rate of fourteen pomegranate cultivars cultivated in Iran.

\begin{tabular}{|c|c|c|c|c|c|}
\hline \multirow[t]{2}{*}{ Cultivar } & \multirow[t]{2}{*}{ Fruit weight (gr) } & \multirow[t]{2}{*}{ skin weight (gr) } & \multirow[t]{2}{*}{ Skin percentage $(\%)$} & \multicolumn{2}{|c|}{ Extraction rate (cc/100gr DW) } \\
\hline & & & & Peel & Pulp \\
\hline Sweet Alac & $199.36 \pm 3.54 \mathrm{~d}$ & $73.59 \pm 1.14 \mathrm{~cd}$ & $36.91 \pm 0.98 \mathrm{~d}$ & $7 \pm 0.54 b$ & $7 \pm 1.01 \mathrm{ab}$ \\
\hline Sour Alac & $193.44 \pm 2.56 \mathrm{de}$ & $65.61 \pm 1.25 \mathrm{~d}$ & $33.92 \pm 0.56 \mathrm{de}$ & $7 \pm 0.98 b$ & $8.5 \pm 1 \mathrm{a}$ \\
\hline Sour malas & $223.35 \pm 2.01 b c$ & $127.41 \pm 2.36 b c$ & $57.04 \pm 0.78 \mathrm{ab}$ & $5.4 \pm 024 \mathrm{c}$ & $4.85 \pm 0.56 \mathrm{~cd}$ \\
\hline Sweet black & $249.33 \pm 3.14 \mathrm{ab}$ & $151.21 \pm 2.54 \mathrm{ab}$ & $60.64 \pm 1.02 \mathrm{a}$ & $9 \pm 1.02 \mathrm{ab}$ & $4.5 \pm 0.49 \mathrm{~d}$ \\
\hline Sour Summer & $178.63 \pm 1.98 \mathrm{e}$ & $58.56 \pm 1.14 \mathrm{~d}$ & $32.79 \pm 0.65 \mathrm{e}$ & $7.5 \pm 0.98 b$ & $7 \pm 1.12 b$ \\
\hline Sour white peel & $265.42 \pm 2.25 \mathrm{a}$ & $169.85 \pm 2.24 \mathrm{a}$ & $63.99 \pm 1.24 \mathrm{a}$ & $5 \pm 0.87$ & $4.2 \pm 0.25 \mathrm{~d}$ \\
\hline Sweet Saveh & $222.97 \pm 3.65 b c$ & $101.12 \pm 1.97 \mathrm{c}$ & $45.35 \pm 1.3 \mathrm{c}$ & $6 \pm 0.55 b c$ & $7.5 \pm 0.88 \mathrm{a}$ \\
\hline Black peel & $219.52 \pm 2.14 \mathrm{c}$ & $98.59 \pm 2.25 c$ & $44.91 \pm 0.96 c$ & $12 \pm 1.35 \mathrm{a}$ & $5.8 \pm 0.33 c$ \\
\hline Sweet white peel & $208.77 \pm 2.25 \mathrm{~cd}$ & $112.26 \pm 1.36$ & $53.77 \pm 2.03 \mathrm{ab}$ & $8.12 \pm 1.09 \mathrm{ab}$ & $6.5 \pm 1.02 \mathrm{bc}$ \\
\hline Agha Mohammad Ali & $234.93 \pm 2.34 b$ & $129.45 \pm 2.34 b$ & $55.1 \pm 2 \mathrm{ab}$ & $4 \pm 0.49 \mathrm{~d}$ & $6.4 \pm 1 b c$ \\
\hline Sweet Shahsavar & $275.41 \pm 1.47 \mathrm{a}$ & $132.25 \pm 1.45 b$ & $48.01 \pm 1.43 b c$ & $6 \pm 0.25 b c$ & $5.5 \pm 0.66 \mathrm{c}$ \\
\hline Robab & $251.45 \pm 1.12 \mathrm{ab}$ & $116.17 \pm 2.15 b c$ & $46.2 \pm 1.27 \mathrm{bc}$ & $4 \pm 0.44 d$ & $5 \pm 0.44 \mathrm{~cd}$ \\
\hline Yousef khani & $195.79 \pm 1.25 \mathrm{de}$ & $86.49 \pm 1.24 \mathrm{~cd}$ & $44.17 \pm 1.27 \mathrm{~cd}$ & $5.5 \pm 0.69 \mathrm{c}$ & $7.1 \pm 1.1 \mathrm{ab}$ \\
\hline Sweet Aghdaei & $315.63 \pm 2.14 \mathrm{a}$ & $156.12 \pm 2.31 \mathrm{a}$ & $49.46 \pm 0.69 b$ & $5.4 \pm 1.23 \mathrm{~cd}$ & $4.4 \pm 0.26 \mathrm{~d}$ \\
\hline
\end{tabular}

In each column values with the same letter $(a, b, c, d$ and e) are not significantly different $(p>0.05)$ using Tukey.

mixed for 4 hours. 10 milliliters of distilled water was added to the resulting solution, that was stored in a refrigerator until evaluation. To evaluate the amount of ascorbic acid (vitamin C), the 2, 6-chlorophenol endophenol method was implemented.

Total Tannin

To prepare a tannic acid solution, first, $25 \mathrm{mg}$ of tannic acid was dissolved in $25 \mathrm{ml}$ of sterilized distilled water and with several dilutions of tannic acid a standard curve was determined using the Broadhurst method. ${ }^{7}$

Total flavonoid

Total flavonoid content was determined using the aluminum chloride colorimetric method. ${ }^{8}$

\section{Antioxidant activity}

Diphenyl-1-picrylhydrazyl (DPPH) standard protocol was used to evaluate the antioxidant activity. ${ }^{9}$

Total phenolic compounds

Total phenolic compounds were determined according the Folin-Ciocalteu standard method. ${ }^{10}$

Anthocyanin quantitation

$500 \mu \mathrm{l}$ of extracts were diluted with $10 \mu \mathrm{L}$ of hydrogen chloride $1 \%$ in methanol (1 to 99 ). The solution was stored in dark at room temperature for 24 hours. Then the optical absorption was determined at $530 \mathrm{~nm}$. The results were reported in milligrams per 100 grams of dry pulp. ${ }^{11}$

\section{Results}

Table 1 shows the results of fruit and exocarp weight and the percentage of exocarp. The results of the average efficiency for extraction in ethanol, methanol and water extracts of tannin are reported. The highest amount of tannin extracts resulted from the ethanol extract of the Black Peel exocarp $(201.76 \pm 1.93)$, and the lowest amount of tannin from the aqueous extracts of Yousef Khani pulp (24.15 \pm 1.48$)$. The highest flavonoid activity was in ethanol extract of Sweet Alac exocarp (119.69 \pm 1.02), the lowest activity was in aqueous extract of Sweet White Peel $(39.19 \pm 2.35)$. Our data show also that the highest activity is in the ethanol extract of the Black Peel $(95.65 \pm 3.1)$, and the minimum amount in aqueous extract of Robab pomegranate $(17.7 \pm 2.02)$. The highest total phenolic activity was present in the Sour White Peel ethanol extract $(327.05 \pm 863)$, while the aqueous extract of Robab pomegranate pulp had the lowest phenolic activity

Evaluating the 14 Iranian native pomegranate cultivars, we found that the highest percentage of ascorbic acid is found in Sour Alac exocarp extract $(97 \%)$, while the lowest amount was found in Sweet Saveh pulp extract 


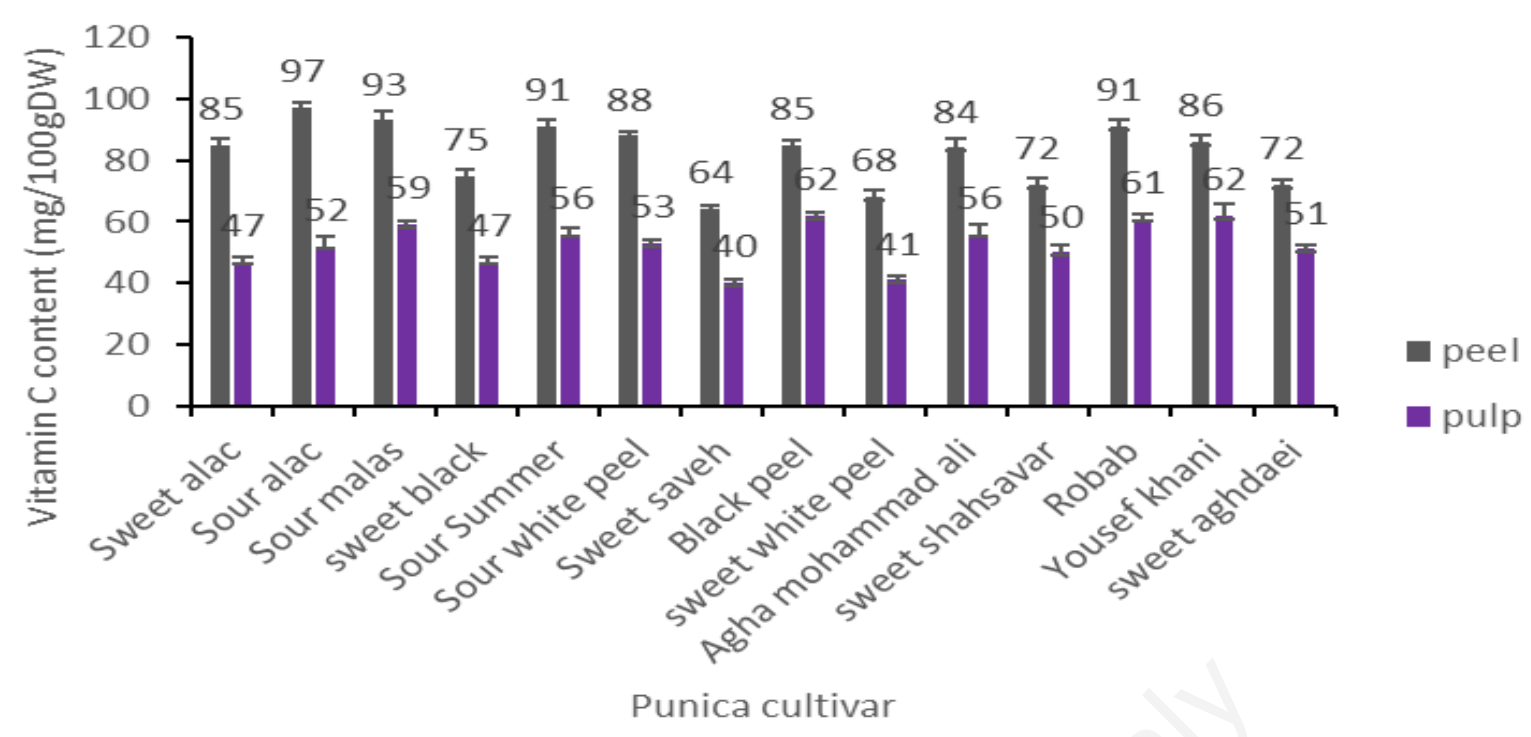

Fig 1. Vitamin C content (mean standard error) of dried peel and pulp of pomegranate varieties. Means followed by different letters are significantly different at $p \leq 0.05$

(40\%) (Figure 1). Investigating the amount of anthocyanin in pulp and exocarp extracts the highest anthocyanin content was found in the Black Peel ethanol extract (22.52 milligrams per 100 grams) (Figure 2).

\section{Discussion}

We analyzed in this study the amount of phenolic compounds and tannins in the exocarp and pulp of 14 types of native Iranian pomegranates cultivars. Several factors, including solvent polarity affect the extraction efficiency, in particular the properties of solvents. For instance, solubility of sugar compounds in alcohols is low, but effectiveness increases with increasing extraction stages. In terms of polarity, ethanol is recognized between completely polar and nonpolar solvents. Anyhow, the most effective extraction in this study was in ethanol solvents.

Several published reports discussed antioxidant activity of different pomegranate's extract. As to the fruit, the extract of the pomegranate's exocarp revealed the highest antioxidant activity in laboratory, that is, in vitro, associated with higher levels of phenolic compounds. These compounds include tannins, flavonoids, alkaloids, organic acids, etc. Phenolic compounds are very strong antioxidants, that can neutralize free radicals, and their cytotoxic effects, plaing an important role in human

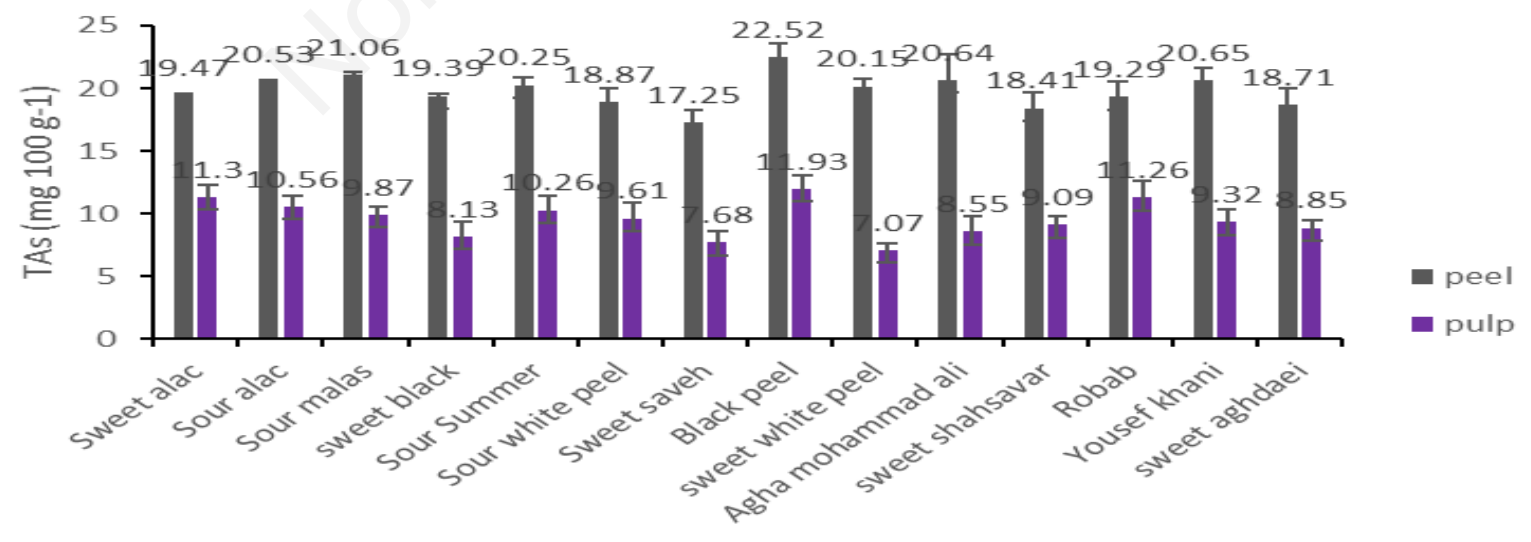

Punica cultivar

Fig 2. Anthocyanin content of dried peel and pulp of pomegranate varieties. Means followed by different letters are significantly different at $p \leq 0.05$. 
health. ${ }^{12}$ Çam et al. report that in methanol extracts of pomegranate exocarp, the phenolic compounds of pomegranate exocarp extract are $258.2 \mathrm{mg} / \mathrm{g}$, and the flavonoids are $18.1 \mathrm{mg} / \mathrm{g} .{ }^{13}$ Zheng et al. report that the phenolic compounds in the ethanol extract of the pomegranate exocarp is $508.98 \mathrm{mg} / \mathrm{g} .{ }^{14}$ Many authors agree that phenolic acids, flavonoids and anthocyanin compounds present in the pomegranate exocarp are responsible of the antioxidant properties of these extracts. The amount of antioxidant properties in ethanol extract of pomegranate was reported by Iqbal to be $89.23,{ }^{13}$ while we found a slight but significant higher content $95.65 \pm 3.1$. Many otmher researchers agre that that ethanol is thebest solvent for extracting antioxidant compounds from pomegranate. ${ }^{15}$ On the other hand, Nasacheva et al., 1973 showed that the exocarp of Indian native pomegranate cultivarsmay reach a total amount of tannin of $300 \mathrm{mg} / \mathrm{g} .{ }^{16}$ As well, Sharma et al. reported that the total tannins in the exocarp of Indian pomegranate cultivars were in between 118.1 and $162.9 \mathrm{mg} / \mathrm{g} .{ }^{17} \mathrm{In}$ contrast, our study on 14 types of native Iranian pomegranates indicates that the highest amount of total tannin is found in ethanol extract of Iranian Black peel exocarp $(201.76 \pm 1.93)$.

Total amount of tannins in pomegranate depends on several factors including climate conditions of the area, species and the method of extraction. Considering that all 14 studied cultivars were grown and harvested in the same climatic, nutritional and gardening operations conditions, the difference in total amount of tannin in the fruit exocarp can be due to high genetic differences between cultivars.

In the present study, the highest amount of vitamin $\mathrm{C}$ was seen in Sour alac pomegranate exocarp (97\%), while in the study of Talaee et al. on six cultivars of native Iranian pomegranate, the highest amount of vitamin $\mathrm{C}$ was reported to be present in Aghaee pomegranate, but in less amount. ${ }^{18}$ In addition, our study indicates that the highest amount of anthocyanin is found in the ethanol extract of black peel pomegranate exocarp, while Talaee et al reported anthocyanin for Aghaee pomegranate to be 27.738 milligrams per 100 milligrams of extract. ${ }^{18}$ It should be noted that, with the progress in growth of the pomegranate fruit, the ascorbic acid content significantly decreases.

As to the biological effects of the extracts, Choudhary et al., 2008 evaluated the wound healing effect of Myrobalan ethanol extract. They concluded that tannins are the most important compounds of this plant, being basically responsible for wound contraction, increased epithelialization, capillary ducts formation, and increase of fibroblasts. ${ }^{19}$ In another study researchers suggested that ethanolic extract has greater anti inflammatory effect compared to the methanolic extract. Therefore, it can be inferred that the anti inflammatory agent in $R$. graveolenss. ${ }^{20}$

According to our study, the pomegranate exocarp contains tannin as well. The presence of this compound is the main reason for the wound healing properties of pomegranate, due to its antimicrobial properties. An extract from the whole plant can show different properties compared to the extract prepared from a specific part of the plant due to the cumulative effects of different compounds. Therefore, the findings of our study are consistent with the described mechanisms of tannins and flavonoids presented in other researches. Ruiz et al., 2007 stated that flavonoids contain anti-inflammatory cytokines, and thus weaken inflammation, ${ }^{21}$ in agreement with previous studies. ${ }^{22-24}$ In related study the result show that various parts of the pomegranate skin have different effects on wound healing in rats. ${ }^{25}$

In conclusion, since our results indicate that high levels of flavonoids are found in the ethanol extract of Sweet Alac exocarp, this extract can be used for producing antiinflammatory drugs for wound healing starting from natural products of the traditional Iranian medicine.

\section{List of acronyms}

DPPH - Diphenyl-1-picrylhydrazyl

\section{Author's contributions}

Each author contributed in equal part to the manuscript.

\section{Acknowledgments}

We would like to thank all those who assisted in the field collection and laboratory processing of samples for this project.

\section{Funding}

This work was supported by AJA university of Medical Sciences, Tehran, Iran, but this research received no other specific grant from any funding agency in the public, commercial or not for profit sectors.

\section{Conflict of Interest}

The authors report no conflicts of interests.

\section{Ethical Publication Statement}

We confirm that we have read the Journal's position on issues involved in ethical publication and affirm that this report is consistent with those guidelines.

\section{Corresponding Author}

Sayid Mahdi Mirghazanfari, Department of Physiology and Iranian Medicine, School of Medicine, AJA University of Medical Sciences, Tehran, Iran,Tel: 00989122765221. Email: smmirghazanfari@gmail.com E-mail of co-author

\section{Mohammad Omidi Ghaleh Mohammadi:} m.omidighale@ut.ac.ir

\section{References}

1. Darvishi M, Sadeghi SS. Evaluation of Association of Helicobacter Pylori Infection and Coronary Heart Disease (CHD) among CCU Patients. Journal of Pure and Applied Microbiology 2016; 10: 262126. 


\section{Wound healing components in Iranian pomegranate cultivars}

Eur J Transl Myol 29 (1): 22-26, 2019

2. Seeram NP, Adams LS, Henning SM, et al. In vitro antiproliferative, apoptotic and antioxidant activities of punicalagin, ellagic acid and a total pomegranate tannin extract are enhanced in combination with other polyphenols as found in pomegranate juice. J Nut Biochem 2005;16:360-7.

3. Kawashty SA, Mosharrafa SA, El-Gibali M, et al. The flavonoids of four Pistacia species in Egypt. Biochem Syst Ecol 2000;28:915-7.

4. Mirghazanfari SM. Assay of pharmacological features of phoenix Dactylifera in the view of traditional and modern medicine. Life Sci 2013;10(7s).

5. Nateqi M, Mirghazanfari SM. Determination of total phenolic content, antioxidant activity and antifungal effects of Thymus vulgaris, Trachyspermum ammi and Trigonella foenum graecum extracts on growth of Fusarium solani. Cell Mol Biol (Noisy le Grand). 2018;64(14):39-46.

6. Hayouni EA, Abedrabba M, Bouix M, et al. The effects of solvents and extraction method on the phenolic contents and biological activities in vitro of Tunisian Quercus coccifera L. and Juniperus phoenicea L. fruit extracts, Food Chemistry 2007;105:1126-34.

7. Chang C, Yang M, Broadhurst RB, et al. Analysis of condensed tannins using acidified vanillin. Journal of the Science of Food and Agriculture 1978; 48(3): 788-94.

8. Chang CC, Yang MH, Wen HM, Chern JC. Estimation of total flavonoid content in propolis by two complementary colorimetric methods. J Food Drug Anal 2002;10:34-8.

9. Parthasarathy S, Bin Azizi J, Ramanathan S, et al. Evaluation of antioxidant and antibacterial activities of aqueous, methanolic and alkaloid extracts from Mitragyna speciosa (Rubiaceae family) leaves. Molecules. 2009;14:3964-74

10. Wojdyło A, Oszmiański J, Czemerys R. Antioxidant activity and phenolic compounds in 32 selected herbs. Food Chemistry 2007;105:940-9.

11. Wall MM. Ascorbic acid, vitamin A, and mineral composition of banana (Musa sp.) and papaya (Carica papaya) cultivars grown in Hawaii. J Food Composition Anal 2006;19:434-45.

12. Salimi F, Shafaghat A, Sahebalzamani H, et al. $\alpha-$ Pinene from Pistacia atlantica Desf. Subsp. kurdica (Zohary) Rech. F. Der Chemica Sinica 2011;2:1-3.

13. Çam M, Hışıl Y. Pressurised water extraction of polyphenols from pomegranate peels. Food chemistry 2010;123:878-85.

14. Zheng W, Wang SY. Oxygen radical absorbing capacity of phenolics in blueberries, cranberries, chokeberries, and lingonberries. J Agricultural Food Chemistry 2003;51:502-9.

15. Iqbal S, Haleem S, Akhtar M, et al. Efficiency of pomegranate peel extracts in stabilization of sunflower oil under accelerated conditions. Food Research International 2008;41:194-200

16. Nasacheva EP, Anisimova KI, Shteinbok SD. Tannins of the pericarp of pomegranate fruits and prospects for their utilization in the tanning industry. Rastitel Resursy 1973.11:56-9.

17. Sharma SD, Sharma VK. Variation for chemical characters in some promising strains of wild pomegranate (Punica granatum L.). Euphytica 1990;49:131-3.

18. Talaei A, Askari M, Bahadoran F, et al. Study the effect of hot water and polyethylene bags on postharvest life and fruit quality of pomegranate cv. Malas-e-Saveh. J Agri Sci 2004;35: 369-77.

19. Choudhary GP. Wound healing activity of the ethanol extract of Terminalia bellirica Roxb. fruits. Indian J Natural Products Resour 2008;7:19-21.

20. Mirghazanfari SM, Abbassian A, Kamalinejad M, Karimian SM, Massoud A. The effect of methanolic and ethanolic extracts of Ruta graveolens L. leaves on formalin-Induced inflammation in Rats. Trad Integr Med 2016; 1:136-41.

21. Ruiz PA, Braune A, Hölzlwimmer $G$, et al. Quercetin inhibits TNF-induced NF- $\kappa \quad B$ transcription factor recruitment to proinflammatory gene promoters in murine intestinal epithelial cells. J Nutrition 2007;137:1208-15.

22. Albertin G, Kern H, Hofer C, et al. Two years of Functional Electrical Stimulation by large surface electrodes for denervated muscles improve skin epidermis in SCI. Eur J Transl Myol 2018;28:7373.

23. Ravara B, Hofer C, Kern H, et al. Dermal papillae flattening of thigh skin in Conus Cauda Syndrome. Eur J Transl Myol 2018;28:386-392.

24. Godfraind C, Debelle A, Lonys L, et al. Inductive Powering of Subcutaneous Stimulators: Key Parameters and Their Impact on the Design Methodology. Eur J Transl Myol 2016;26:6040.

25. Asadi MS, Mirghazanfari SM, Dadpay M, Nassireslami E. Evaluation of wound healing activities of pomegranate (Punica granatumLythraceae) peel and pulp. JRMDS 2018; 6(3), 230236.

Submission: 11 December 2018

Revisions received: 08 January 2019

Acceptance: 08 January 2019 